\title{
Panorama atual e perspectivas futuras das agroindústrias familiares no Rio Grande do Sul
}

\author{
Cristian Rogério Foguesatto ${ }^{1}$ \\ Felipe Dalzotto Artuzo ${ }^{2}$ \\ João Armando Dessimon Machado ${ }^{3}$
}

\section{RESUMO}

A agricultura familiar é caracterizada no cenário brasileiro por sua importância na economia, sendo que a agroindústria familiar surge como alternativa para maximizar o desenvolvimento econômico do contexto familiar rural. Nesse sentido, considerando a relevância das atividades agroindústrias familiares esse estudo tem por objetivo analisar as percepções de atores-chave sobre a situação atual dessas atividades e sua perspectiva no âmbito organizacional, com enfoque no Estado do Rio Grande do Sul (RS). A pesquisa foi realizada com nove atoreschave (indivíduos que trabalham no setor agroindustrial familiar ou que já desenvolveram estudos sobre o tema). Medidas institucionais como o aumento no número de redes de cooperação (cooperativas e associações), a adequação tecnológica e o desenvolvimento de novos nichos de mercados, voltados principalmente para a segurança alimentar, foram às tendências apresentadas pelos atores-chave para o futuro do setor agroindustrial familiar do RS.

Palavras-chave: Agricultura Familiar, Agroindústria Familiar, Desenvolvimento Regional, Diversificação.

\section{Current context and future perspectives of family agroindustries in Rio Grande do Sul}

\begin{abstract}
Family farming is a sector of relevant importance in the Brazilian economy and the family agroindustry arises as an alternative to maximize economic development. Considering the relevance of the family agroindustry activities, this study aims to analyze the perceptions of key actors on the current situation of agroindustrial activities and organizationally perspectives for the next years, in the Rio Grande do Sul (RS) State. The survey was conducted with nine key actors (people that working in the family agroindustrial sector or that studied the family agroindustries context). Institutional measures such as the increase in the number of cooperation networks (cooperatives and associations), technological adaptation and development of new niche markets, geared mainly to food security, were the trends presented by key actors for family agroindustrial sector's future in RS.
\end{abstract}

Keywords: Family farm, Family agroindustry, Regional Development, Diversification.

\footnotetext{
${ }^{1}$ Doutorando em Agronegócios (PPG-Agronegócios/UFRGS). Mestre em Agronegócios pela UFRGS. Graduado em Administração pela UFSM. Tem experiência nas áreas de Gestão Agrícola e Agroindustrial, atuando nos seguintes temas: análises comportamentais, desenvolvimento local e regional. Atualmente é tutor do Bacharelado em Desenvolvimento Rural (UFRGS). E-mail: cristian.foguesatto@ufrgs.br

${ }^{2}$ Doutorando em Agronegócios (PPG-Agronegócios/UFRGS). Mestre em Agronegócios pela UFRGS. Graduado em Agronomia pela UFSM e em Administração pela UFSC. Tem experiência na área da agronomia e administração, atuando principalmente nos seguintes temas: análise de inovação tecnológica no agronegócio, cadeias produtivas, impacto ambiental das inovações tecnológicas e gestão e administração rural. Participante dos grupos de pesquisas em bioeconomia, controladoria, contabilidade e custos em organizações do agronegócio. ${ }^{3}$ Possui graduação em Medicina Veterinária (UFRGS), mestrado em Economia Rural pela UFRGS e doutorado em Economia Agroalimentar pela Universidade de Córdoba/Espanha. Atualmente é professor associado da UFRGS atuando na Graduação, no Pós-Graduação em Desenvolvimento Rural e no Pós-Graduação em Agronegócios.
} 


\section{INTRODUÇÃO}

A importância e a caracterização da agricultura familiar brasileira são objetos de interesse de inúmeras pesquisas, em diversas áreas do conhecimento. Se por um lado o setor se destaca pela produção de alimentos, geração de renda e inclusão social, por outro, enfrenta desafios para sua sustentabilidade. Entre esses desafios, ressalta-se a ocorrência da insatisfação dos agricultores familiares perante aos resultados econômicos obtidos por meio das atividades agrícolas (WESZ JUNIOR, 2009). Assim, sob a influência de fatores como a instabilidade climática, flutuação no preço de insumos, baixa escala de produção, obsolescência tecnológica e as oscilações da economia, parte dos agricultores familiares buscam alternativas produtivas para manter uma condição de vida adequada no meio rural. Nesse contexto, as atividades pluriativas emergem como estratégicas.

A pluriatividade na agricultura familiar refere-se às situações onde os indivíduos que compõem a família passam a realizar outras atividades econômicas e produtivas caracterizadas como não-agrícolas, praticadas dentro ou fora das propriedades (SCHNEIDER, 2003). Entre essas atividades, às voltadas à agregação de valor dos produtos agropecuários in natura (como as agroindústrias familiares) vêm se destacando (FOGUESATTO; MACHADO, 2017a).

As principais características das agroindústrias familiares rurais, que as diferem das tradicionais e de outros tipos de organizações produtivas, são: i) os membros devem possuir laços de parentesco; ii) a utilização de máquinas e equipamentos é em escala menor; iii) a procedência de matéria-prima é própria ou adquirida de vizinhos; e iv) deve estar localizada no meio rural (MIOR, 2005). Em sua maioria, os produtos agroindustriais familiares possuem baixo conteúdo tecnológico, entretanto, apresentam expressivo potencial de agregação de valor (RUIZ et al., 2002).

Essas atividades têm apresentando importante papel em relação à temática do desenvolvimento regional. Nessa perspectiva, foram criados instrumentos de políticas públicas como o Programa Estadual de Agroindústria Familiar/RS (PEAF), transformado em Política Estadual de Agroindústria Familiar, criado em 2012 (RIO GRANDE DO SUL, 2013) e o Programa Nacional de Fortalecimento da Agricultura Familiar (PRONAF) - linha Agroindústria. Com base nesse panorama, o artigo tem por objetivo analisar as percepções de atores-chave sobre a situação atual das atividades agroindustriais familiares e a sua perspectiva no âmbito organizacional no Estado do Rio Grande do Sul (RS). 


\section{REFERENCIAL TEÓRICO}

\subsection{Panorama geral da agricultura familiar brasileira}

Levando em consideração a sua importância social e econômica, o ano de 2014 foi considerado o Ano Internacional da Agricultura Familiar. Estipulado pela Organização das Nações Unidas (ONU), esse marco teve como objetivos, por exemplo, promover e evidenciar o desenvolvimento de políticas públicas que auxiliem as unidades produtivas familiares e ressaltar o papel estratégico dos agricultores familiares frente ao desenvolvimento agrícola e rural.

No Brasil, a agricultura familiar tem importante papel econômico. Conforme o Instituo Brasileiro de Geografia e Estatística (IBGE, 2009) aproximadamente 84\% dos estabelecimentos agropecuários são classificados como familiares, representando $33 \%$ do Produto Interno Bruto (PIB) do país, o que ressalta o seu importante papel, tanto pela produção de alimentos, quanto na geração de empregos diretos e indiretos.

Além de conter no máximo quatro módulos fiscais ${ }^{4}$, o estabelecimento agrícola familiar é definido como aquele em que a gestão, a propriedade e a maior parte da força de trabalho são oriundas de indivíduos que mantêm entre si laços de sangue ou de matrimônio (ABRAMOVAY, 1998). Veiga (1996) corrobora afirmando que as atividades agrícolas familiares apresentam perfis essencialmente distributivos, levando em consideração aspectos socioeconômicos e a maleabilidade no processo decisório.

Nos últimos anos, esses estabelecimentos passaram a ter maior destaque no âmbito organizacional e institucional. Com esse enfoque, discussões sobre agricultura familiar vêm ganhando legitimidade social, política e acadêmica no Brasil, passando a ser utilizada com maior frequência por movimentos e estudiosos das Ciências Sociais que se ocupam da agricultura e do meio rural (SCHNEIDER, 2003). Nesse contexto, dentre os acontecimentos de maior ênfase, destaca-se a criação do PRONAF (em meados dos anos 1990), destinado a estimular a geração de renda e melhorarias na mão de obra familiar (SCHNEIDER; CAZELLA; MATTEI, 2004). Além disso, em 2011, o governo implementou o Programa Rede Rural Brasil, com a finalidade de aproximar os agricultores de outros elos da cadeia em que estão inseridos (como fornecedores, logística de transporte e os consumidores), visando maximizar a organização da cadeia de produtos da agricultura familiar (CARVALHO; SANTOS; CARVALHO, 2015).

\footnotetext{
${ }^{4}$ Medida que varia de cinco a 110 ha, conforme a localização geográfica do município (LANDAU et al., 2012).
} 
Apesar desse reconhecimento, as propriedades familiares têm apresentado desafios em suas trajetórias (WESZ JUNIOR, 2009). O pequeno agricultor possui uma restrita gama de alternativas para comercializar sua produção sem depender de intermediários (WESZ JUNIOR, 2009). Também, em virtude da instabilidade climática, não ocorrência da sucessão hereditária, variação no preço dos insumos e da comercialização da produção, por vezes, apenas os rendimentos das atividades agropecuárias são economicamente insatisfatórios. Fazse necessário, então, a busca por alternativas produtivas, com o intuito de desenvolver e viabilizar a agricultura familiar, além da busca pelo desenvolvimento regional. Nesse sentido, Schneider (2003) destaca a realização de atividades pluriativas como importante estratégia. Entre essas atividades, as agroindústrias familiares destacam-se, contribuindo na manutenção da renda da família rural (FOGUESATTO; MACHADO, 2017a).

\subsection{Diversificação das atividades rurais: as agroindústrias familiares}

O meio rural deixou de ser sinônimo de agrícola, e passou também, a ser local de atividades que eram tipicamente urbanas (BASALDI, 2001). Em outras palavras, no contexto produtivo rural, com o passar dos anos surgiram diferentes atividades (inclusive às que eram restritas ao meio urbano) que possibilitaram uma renda adicional ao produtor. Dessa forma, desenvolveu-se no rural uma diversificação de atividades. Essa diversificação consiste em selecionar um portfólio de atividades visando à estabilização dos fluxos de renda e de consumo (KAGEYAMA, 2003).

O termo diversificação é conceituado em seu sentido estrito e associa-se à multifuncionalidade. Entretanto, salienta-se a diferença entre diversificação rural e diversificação agrícola. O primeiro caso refere-se à implantação simultânea de atividades agrícolas e não-agrícolas em uma propriedade, já na diversificação agrícola, ocorre a implementação de duas ou mais atividades agrícolas. Nesse portfólio de atividades, incluemse aquelas desenvolvidas dentro da porteira (on-farm) - como a produção agropecuária, agroindustrial e outras atividades não-agrícolas - e as que são desenvolvidas fora da porteira (off-farm) - como arrendamentos, empregos, benefícios sociais, aposentadorias, entre outras (ELLIS, 1998).

Destaca-se então, que as estratégias na busca pela geração de renda, pautadas na diversificação das atividades, são entendidas a partir da pluriatividade (TERNOSKI; PERONDI, 2014). Assim, como já mencionado, em virtude das características da agricultura familiar brasileira, a pluriatividade na agricultura familiar torna-se necessária. A 
pluriatividade segue caminho conceitual inverso ao da monoatividade, visto que se refere a estabelecimentos que buscam diversificar estratégias, por meio de atividades não-agrícolas (TERNOSKI; PERONDI, 2014). Apesar dos sistemas diversificados apresentarem uma gestão caracterizada por um maior grau de complexidade, a redução dos riscos e das incertezas é considerada uma vantagem, sendo que a sua adoção pode gerar ganhos econômicos de forma direta ou indireta (PELINSKI et al., 2006). A Figura 1 apresenta uma propriedade diversificada e uma especializada.

Figura 1 - Exemplo de propriedade diversificada (atividades agrícolas e não-agrícolas) e especializada

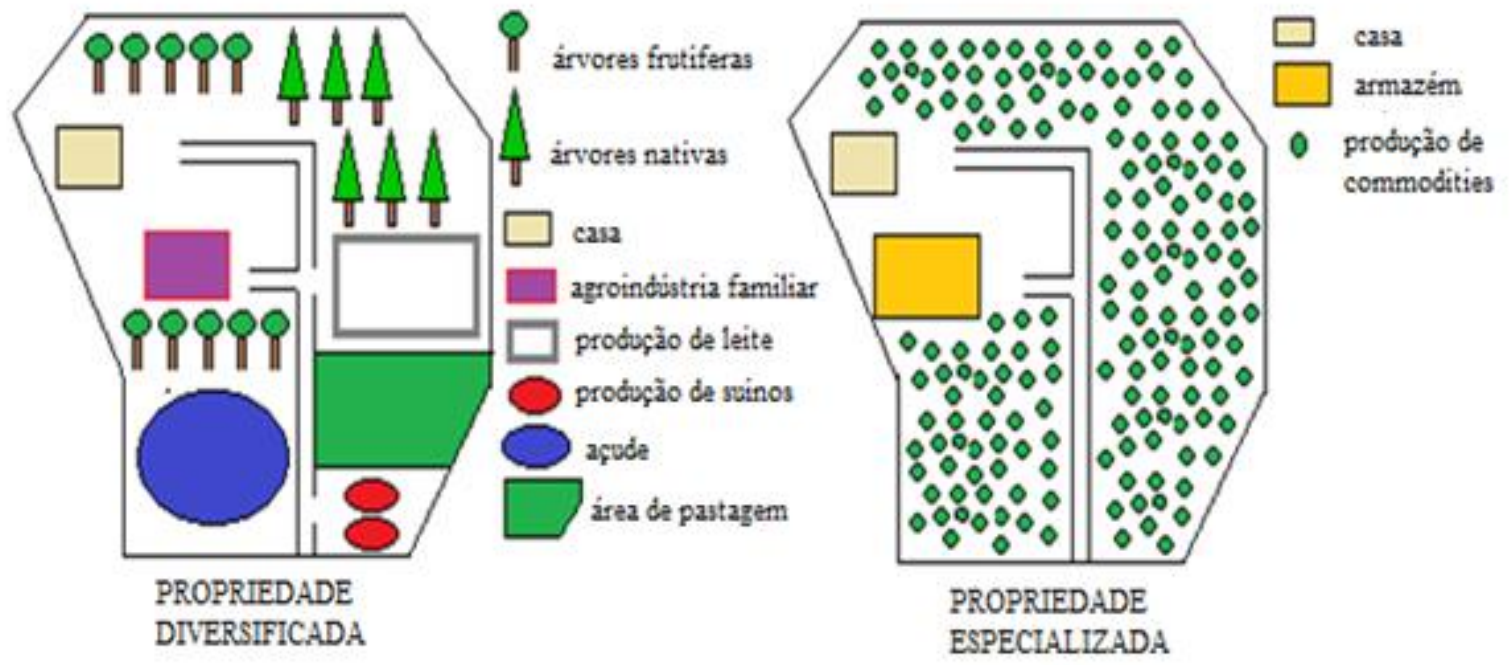

Fonte: elaborada pelos autores com base em Ellis (1998).

Quando uma propriedade diversificada, que tem como produção principal atividades agropecuárias e agroindustriais pode ocorrer uma diversificação vertical ${ }^{5}$, com agregação de valor à produção (PELINSKI et al., 2006). Assim, a agroindústria familiar pode surgir como alternativa para a busca de novos nichos de mercado, desenvolvendo iniciativas capazes de gerar novas opções frente aos mercados agroalimentares (NEITZKE; FAVARÃO; SANTOS, 2014).

A agroindústria é uma unidade empresarial onde ocorrem as etapas de beneficiamento, processamento e transformação de determinadas matérias-primas, até a etapa de comercialização (ARAÚJO, 2005). Geralmente as agroindústrias familiares são micro ou pequenas organizações (BREITENBACH et al., 2017), que se reproduzem a partir de três princípios: i) economia voltada para pequena escala de processamento dos produtos agropecuários; ii) modelo e agroindustrialização descentralizado, ou seja, tais

\footnotetext{
${ }^{5}$ Realização de diversas etapas de produção do produto a ser agroindustrializado.
} 
empreendimentos estão pulverizados em diferentes locais; e iii) o desenvolvimento destas atividades por meio de uma qualidade ampla que, além dos aspectos formais de produção e comercialização, seriam considerados pelo consumidor aspectos culturais, sociais e ecológicos (PREZOTTO, 2002).

Panificados, massas, suco de frutas, vinhos, melado, geléias, rapaduras, queijo e embutidos são exemplos de produtos produzidos em agroindústrias familiares (FOGUESATTO; MACHADO, 2017a). Tais produtos, quando apresentam características diferenciadas em comparação aos produtos produzidos em grande escala por corporações industriais, permitem aos produtores a obtenção de um preço superior. Assim, as agroindústrias familiares emergem como unidades produtoras de novidades (Figura 2), gerando processos de transição e/ou incremento no regime alimentar vigente e hegemônico (GAZOLLA; SCHNEIDER, 2015).

Figura 2 - Novidades desenvolvidas pelas agroindústrias familiares

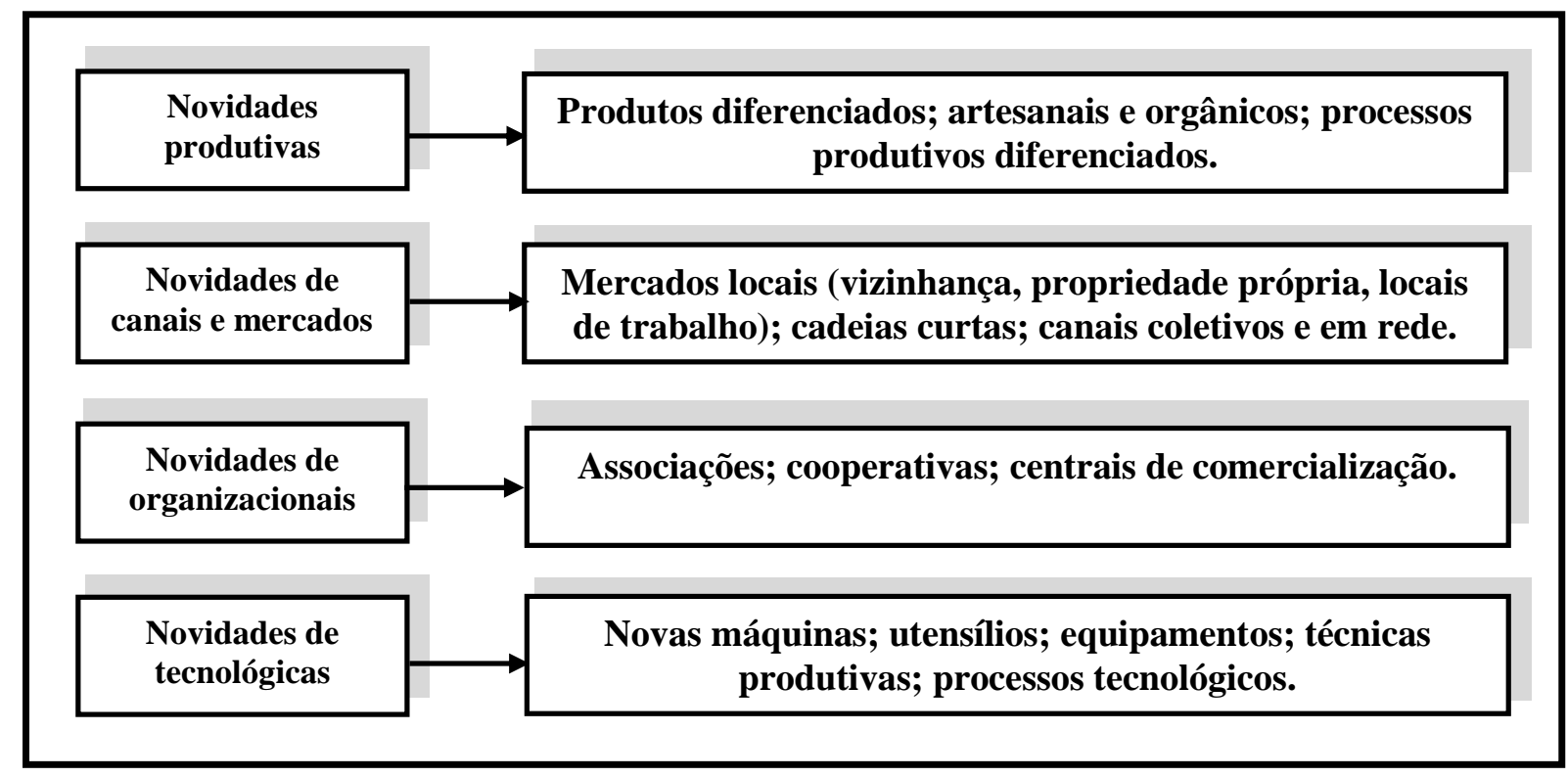

Fonte: Adapatdo de Gazolla (2012).

Em linhas gerais, essas novidades (produtivas, de canais de mercado, organizacionais, e tecnológicas), contribuem para o desenvolvimento da atividade, frente ao mercado contemporâneo. Contudo, essa opção de negócio envolve também a competição com outras organizações da mesma natureza em um mercado complexo. A partir desse embasamento, as características do cenário agroindustrial familiar devem ser estudadas e compreendidas pelos tomadores de decisões desse setor, para que as atividades de agregação de valor atinjam os objetivos pretendidos pelo eixo familiar. 


\section{PROCEDIMENTOS METODOLÓGICOS}

Trata-se de um estudo qualitativo, desenvolvido a partir de dados primários. A coleta de dados foi realizada por meio da aplicação de questionários. Os respondentes foram os atoreschave do segmento agroindustrial familiar. Considerou-se como atores-chave indivíduos que trabalham no setor agroindustrial familiar ou que já desenvolveram estudos sobre o tema no RS. A amostra é constituída por nove respondentes: oito pesquisadores de unidades agroindustriais familiares ${ }^{6}$ e um extensionista rural da Empresa de Assistência Técnica e Extensão Rural (EMATER) (Tabela 1). O tamanho da amostra foi estipulado em virtude da saturação teórica das respostas. Destaca-se que o fechamento amostral por saturação teórica, é operacionalmente definido quando, na percepção dos pesquisadores, os dados começam a se repetir (FONTANELLA, 2008).

Tabela 1 - Respondentes do estudo

\begin{tabular}{cr}
\hline Respondent & Profissão e Instituição \\
\hline 1 & Administradora/Universidade Federal do Rio Grande do Sul \\
2 & Professora/Universidade Federal do Vale do Jequitinhonha e Mucuri \\
3 & Professora/Universidade Estadual do Rio Grande do Sul \\
4 & Extensionista Rural (EMATER) \\
5 & Professor/Universidade Federal do Rio Grande do Sul \\
6 & Professor/Universidade Regional Integrada do Alto Uruguai e das Missões \\
7 & Professor/Universidade Federal do Rio Grande do Sul \\
8 & Professor/Universidade Federal do Rio Grande do Sul \\
9 & Professor/Instituto Federal Farroupilha
\end{tabular}

Fonte: elaborado pelos autores.

As perguntas realizadas foram: i) Qual a situação atual das agroindústrias familiares do RS? ii) Qual a perspectiva das atividades agroindustriais familiares para os próximos anos? iii) Quais são as características dos indivíduos que realizam os processos agroindustriais familiares? iv) Quais os benefícios das atividades agroindustriais para os indivíduos que as realizam? v) Como os órgãos governamentais podem contribuir para o desenvolvimento dessa atividade?

Os respondentes analisaram o contexto do RS. A justificativa do Estado selecionado se deve pela importância das atividades agroindustriais familiares. Fato esse retratado no

\footnotetext{
${ }^{6}$ Esses pesquisadores possuem o título de Mestre ou Doutor.
} 
âmbito institucional, com o desenvolvimento de políticas públicas e em pesquisas científicas; como as de Pelegrini e Gazolla (2008), Niederle e Wesz Junior (2009), Agne (2010), Winck, et al. (2014), Gazolla e Schneider (2015), Matei e Xavier da Silva (2016), Breitenbach et al., (2017), Foguesatto e Machado (2017a), Foguesatto e Machado (2017b).

\section{ANÁLISE E DISCUSSÃO DOS RESULTADOS}

A análise e discussão dos resultados foi estruturada em dois tópicos. O primeiro apresenta características gerais das atividades agroindustriais familiares. E, o segundo, aborda informações referentes às perspectivas do cenário futuro das atividades agroindustriais familiares, com enfoque no âmbito organizacional da unidade produtiva.

\subsection{Características gerais das atividades agroindústrias familiares}

De forma geral, há um consenso entre os atores-chave sobre o importante papel das agroindústrias familiares nos estabelecimentos familiares rurais, alcançado pela agregação de valor, por meio dos processos de diferenciação dos produtos provenientes das atividades agropecuárias. Além disso, também merece destaque a importância das agroindústrias familiares ao longo das últimas décadas, por seu papel social diante da permanência da tradição do "saber-fazer" (know-how) das famílias (RESPONDENTE 1). Ressalta-se, que os processos de agroindustrialização familiar no Brasil emergem a partir do período de modernização da agricultura (WINCK et al., 2014), que iniciou na década de 1950 e se acentuou a partir da década seguinte (TEIXEIRA, 2005).

Também há um consenso entre os respondentes sobre a importância econômica dessas organizações. Nesse sentido, Ruiz et al., (2002) e Foguesatto e Machado (2017a) enfatizam que os agricultores que se dedicam a essas atividades agroindustriais são motivados por fatores econômicos, como é ressaltado na sequência.

A partir das diferenças dos perfis dos agricultores familiares, a agroindústria familiar pode ser: i) de pequena escala, com pretensão de aumento de renda, mas voltada principalmente para as atividades de processamento de alimentos, visando, em suma, o consumo da família; ou ii) desenvolvida com a perspectiva principal de geração de lucro (RESPONDENTE 1). Nesse segundo caso, os agricultores apresentam características 
empreendedoras, possuindo visão de mudança, transformando sua atividade para atender as exigências do mercado, a partir da venda da produção agroindustrial (RESPONDENTE 1).

As atividades de agroindustrialização podem ser inovadoras, com uma gama de produtos com potencial para atender o mercado (RESPONDENTES 3 e 6). Assim, os processos inovativos, na confecção dos produtos agroindustriais, podem resultar em produtos com características específicas e, consequentemente, com maior valor agregado (GAZOLLA, 2012). Por exemplo, se a agroindústria familiar diferenciasse os tipos de queijos fabricados (e não somente produzisse queijo colonial), poderia maximizar a sua remuneração, atendendo outros nichos de mercado (GAZOLLA, 2012).

Em relação à comercialização dos produtos agroindustriais, a herança de conhecimentos específicos relacionados à cultura local e regional, em paralelo com informações adquiridas por meio de iniciativas de capacitação, oferecidas pelos órgãos públicos, é um fator que pode fomentar as vendas (RESPONDENTES 1, 2, 3 e 8). Outro fator que também pode estimular a comercialização são as relações entre os atores da agroindústria e o consumidor final. Essa relação tem papel relevante para a maximização da confiança e da familiaridade entre as partes. Dessa forma, a venda direta (cadeia curta) é considerada um importante canal de comercialização (RESPONDENTES 1, 2 e 3).

A venda direta, que, por vezes, é realizada na própria vizinhança, é conhecida como "venda porta a porta". Em linhas gerais, o maior grau de "conexão" entre o setor agroindustrial familiar e o consumidor final, contribui para o aumento dos retornos financeiros do agricultor, visto que não existem atravessadores, como, por exemplo, redes de varejo (RESPONDENTE 8).

No que condiz aos processos produtivos, atualmente, muitas unidades agroindustriais familiares desenvolvem suas atividades de maneira informal e sem fiscalização sanitária, havendo algumas vezes, precariedade nos equipamentos e nas instalações, necessitando de investimentos e adequações (RESPONDENTES 1, 3, 6, 8 e 9). Esse ambiente aumenta a probabilidade de contaminações e outras variáveis negativas referentes à segurança alimentar. Entretanto, ressalta-se que nos últimos anos, o número de agroindústrias que realizam seus processos de produção de acordo com determinadas normas ${ }^{7}$ (vinculadas a selos, registros e certificações) aumentou de forma expressiva (RESPONDENTES 1, 3, 6, 8 e 9). Nesse sentido, o auxílio de assistência técnica merece destaque (RESPONDENTES 1, 3, 6, 8 e 9). O

\footnotetext{
${ }^{7}$ Em seu estudo, Agne (2010) ressalta que a obtenção de normas regulamentadoras com enfoque para questões sanitárias é a principal dificuldade para os agricultores familiares, visto que determinadas mudanças para o cumprimento de tais normas podem representar de maneira inicial inviabilidade econômica.
} 
desenvolvimento de políticas públicas, juntamente com programas da Secretaria de Desenvolvimento Rural, Pesca e Cooperativismo (SDR) e da EMATER, podem contribuir no fomento para a adequação às normas sanitárias.

Entre as políticas públicas, elencam-se três: i) o PEAF (apontado pelo RESPONDENTE 5); ii) o Programa de Aquisição de Alimentos (PAA) e; iii) o Programa Nacional de Alimentação Escolar (PNAE). O PEAF proporciona diversos instrumentos de fomento para agroindústria familiar, como: linhas de créditos para os agricultores familiares com juros mais baixos; oportuniza a participação dos agricultores familiares no PAA e do PNAE; disponibilizam de locais de comercialização; contribui na formação de associações e cooperativas, entre outros (RIO GRANDE DO SUL, 2013).

Com base neste primeiro tópico, nota-se que os processos agroindustriais transformam o conjunto de costumes e hábitos fundamentais da família rural, modificando por vezes, seus traços comportamentais, influenciados por "novas" práticas produtivistas. Essa mudança pode impactar na construção/desenvolvimento de novo elos, na óptica das atividades produtivas, a partir de uma racionalidade industrial que não vislumbra apenas a produção de matérias-primas, mas sim, todas as fases da cadeia de produção agroindustrial (RESPONDENTE 8) (Figura 3).

Figura 3 - Esquema de cadeia agroindustrial familiar

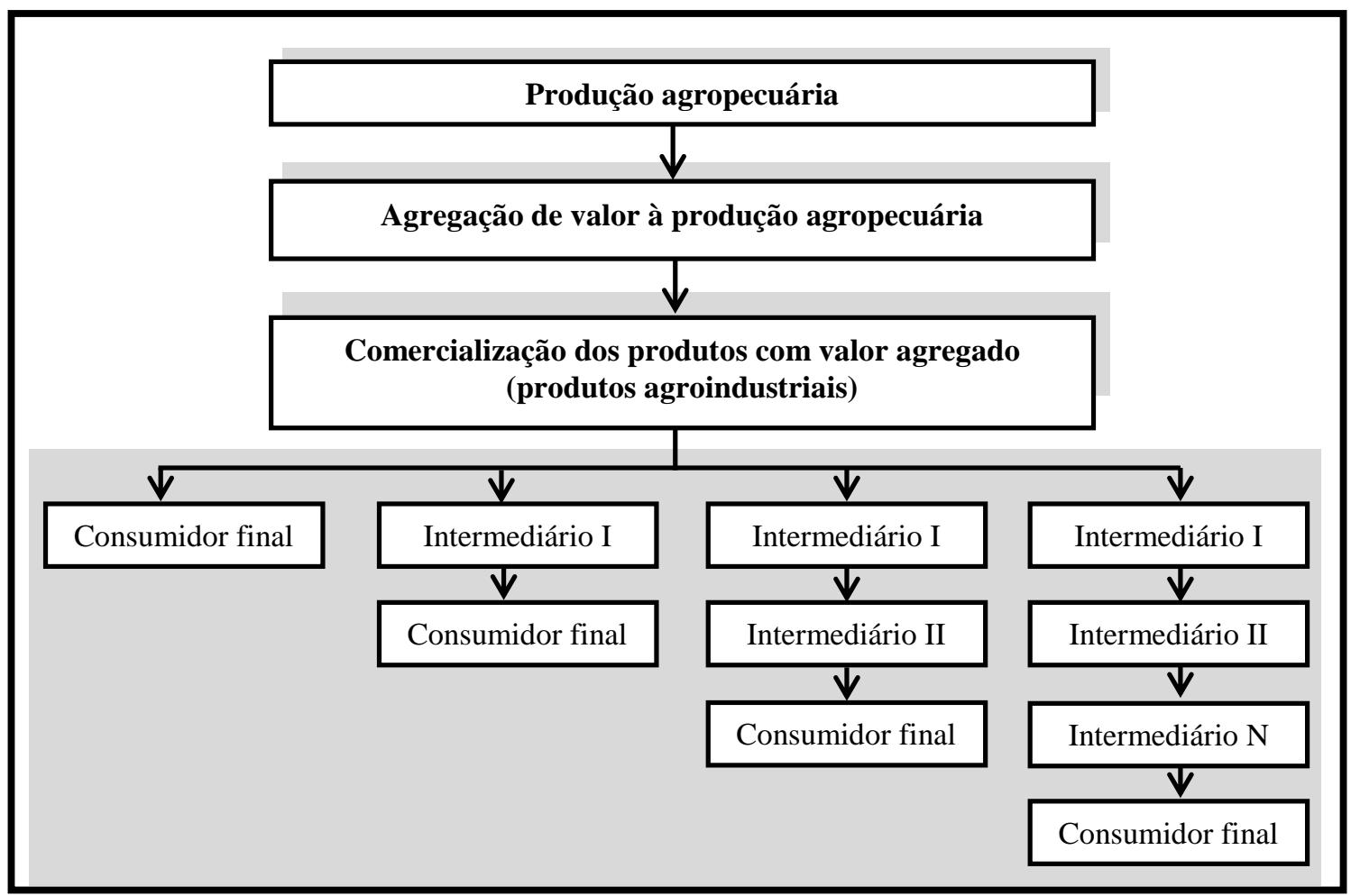

Fonte: adaptado pelos autores com base em Waquil, Miele e Schultz (2010). 
A percepção dos atores-chave sobre o panorama atual das agroindústrias familiares evidencia-se o relevante grau de complexidade dessas organizações nos dias atuais. Portanto, é imprescindível a compreensão de variáveis organizacionais e institucionais nesse contexto (RESPONDENTES 1 e 5). Entre essas variáveis, destacam-se: pesquisa de mercado, planejamento produtivo, análise de canais de distribuição e de comercialização, e adequações a determinadas normas estipuladas pelo governo (RESPONDENTES 1 e 5).

\subsection{Perspectivas do cenário das atividades agroindustriais familiares}

Para os atores-chave, o cenário futuro das agroindústrias familiares depende de qual papel e importância a sociedade lhe atribuirá; e em qual medida os gestores públicos terão capacidade técnica, a fim de resguardar os interesses do setor. Em relação ao presente, as unidades agroindustriais precisarão de suporte e "proteção" estatal, visto que a atividade pode torna-se inviável, quando submetida às mesmas normas que outras atividades do setor industrial agroalimentar (RESPONDENTE 1).

Se o apoio institucional for mantido e/ou aprimorado, as agroindústrias familiares terão maiores condições de impulsionar o desenvolvimento local/regional (RESPONDENTES 1 e 2). Assim, alguns exemplos de incentivos citados pelos atores-chave foram: i) a criação de novos projetos; ii) o desenvolvimento de programas e políticas que facilitem aspectos legais relacionados ao porte, às condições sanitárias, ambientais e tributárias; iii) o desenvolvimento de estratégias de comercialização e de fomento à gestão organizacional; e iv) o aumento no número de redes de cooperação e associativismo entre os agentes envolvidos na transformação da produção, com o objetivo de aumentar o grau de fortalecimento dos processos produtivos e das estratégias de comercialização.

Com o objetivo de aumentar o grau de fortalecimento dos processos produtivos e das estratégias de comercialização, o aumento no número de redes merece ser evidenciado (RESPONDENTES 8 e 9). A cooperação interorganizacional, no formato de redes, é uma estratégia considerada adequada, visto que é por meio de ações coletivas que as organizações, em um âmbito geral, possuem maiores probabilidades de maximizarem seu desempenho competitivo (FENSTERSEIFER, 2000).

A organização em redes é pertinente para resolver entraves referentes à certificação e sanidade dos produtos (AGNE, 2010). Além disso, a inserção em redes tornar-se-ia fundamental para a permanência no mercado, visto que, na maioria dos casos, as 
agroindústrias familiares são negócios caracterizados como pequenos ou médios. Nesse sentido, estratégias coletivas apresentam vantagens, como o aprendizado mútuo no desenvolvimento de processos e produtos, redução dos riscos de incerteza e ganhos a partir de economia de escala ${ }^{8}$ (BALESTRIN; VERSCHOORE, 2008). Para tanto, manter-se informado sobre o desenvolvimento tecnológico é imprescindível, principalmente no que tange à adequação de novas máquinas e/ou equipamentos que auxiliem nos processos de agregação de valor, bem como novas práticas produtivas (RESPONDENTE 8). Com isso, a utilização da internet terá maior importância na construção e no fortalecimento do sistema de informação entre fornecedores, colaboradores e consumidores (RESPONDENTE 8).

Por fim, espera-se que as agroindústrias familiares encontrem cada vez mais espaços no âmbito da comercialização (como feiras, prateleiras em supermercados exposições industriais e agropecuárias), visto que os atributos "artesanal", "colonial" e" "natural" estão cada vez mais valorizados pela população (RESPONDENTES 8 e 9). Nesse sentido, o aumento do consumo de produtos agroindustriais orgânicos tem se destacado e é caracterizado como uma tendência para os atores-chave. Assim, há uma perspectiva otimista de aumento da demanda por produtos de origem agroindustrial familiar, em virtude da maior exigência em relação aos padrões de qualidade do consumidor. Nesse contexto, a produção de orgânicos pode ser um diferencial (CASTRO NETO et al., 2010).

\section{CONCLUSÃO}

As atividades pluriativas de agregação de valor aos produtos agropecuários in natura possuem importante papel econômico na agricultura familiar. Diversos estudos vêm contemplando essa temática, que, tanto no cenário atual quanto em perspectivas futuras, pode ser considerada como uma atividade estratégica e relevante para o desenvolvimento local e regional.

As agroindústrias podem ser agrupadas em dois segmentos: de pequena escala, (visando renda, mas, principalmente a subsistência alimentar do eixo familiar) e aquelas que visam à geração de renda como objetivo principal. Com a criação e desenvolvimento das agroindústrias familiares, o agricultor familiar passa a realizar atividades características do empreendedorismo agroindustrial, devendo estar atento aos elos de interesse dessa cadeia.

\footnotetext{
${ }^{8}$ A economia de escala nesses casos apresenta potencial para contribuir na aquisição de insumos e na diluição de custos nas etapas de agroindustrialização e comercialização.

${ }^{9}$ Produto colonial faz referência a certa cultura e tradição ligadas ao saber-fazer dos imigrantes da Europa não ibérica. Embutidos, queijos e vinhos são alguns exemplos (DORIGON, 2010).
} 
Espera-se que, nos próximos anos, fatores como: apoio institucional, redes de colaboração (cooperativas e associações), manter-se informado sobre questões tecnológicas e o desenvolvimento de novos nichos de mercado voltados principalmente à segurança alimentar contemplem o contexto desse segmento.

De maneira geral, a percepção dos atores-chave é amplamente positiva, sendo que, com a adequação dos elementos destacados nas perspectivas futuras do setor, a atividade tem condições de se tornar ainda mais promissora. Por fim, além de manter a tradição do "saberfazer" das famílias, as atividades agroindustriais familiares fortalecem as condições financeiras do agricultor familiar, que deixa de ser um tomador de preço do mercado, passando a ter maior autonomia nas relações de compra de insumos e na venda da sua produção.

\section{REFERÊNCIAS}

ABRAMOVAY, R. Agricultura familiar e serviço público: novos desafios à extensão rural. Cadernos de Ciência \& Tecnologia, Brasília, v. 15, n. 1, p. 132-152, 1998.

AGNE, C. L. Agroindústrias rurais familiares e a rede de relações sociais nos mercados de proximidade na região Corede Jacuí Centro/RS. 164 f. Dissertação (Mestrado em Desenvolvimento Rural), Programa de Pós-Graduação em Desenvolvimento Rural. Universidade Federal do Rio Grande do Sul, Porto Alegre, 2010.

ARAÚJO, M. J. Fundamentos de agronegócios. São Paulo: Atlas, 2005.

BALESTRIN, A.; VERSCHOORE, J. Redes de cooperação empresarial: estratégias de gestão na nova economia. Porto Alegre: Bookman, 2008.

BALSADI, O. V. Mudanças no meio rural e desafios para o desenvolvimento sustentável. São Paulo em perspectiva, v. 15, n. 1, p. 155-165, 2001.

BREITENBACH, R.; BÜNDCHEN, A.; BRANDÃO, J. B.; CAIRES, L. M. Perception of performance and importance to consumers agro-industry of family companies in the northern region of Rio Grande do Sul state. Ciência Rural, v. 47, n. 5, p. 1-7, 2017.

CARVALHO, C. de O.; SANTOS, A. C. dos; CARVALHO, G. R. Rede Brasil Rural: inovação no contexto da agricultura familiar. Revista em Agronegócio e Meio Ambiente, v. 8, n. 1, p. 79-94, 2015.

CASTRO NETO, N. et al. Produção orgânica: uma potencialidade estratégica para a agricultura familiar. Revista Percurso, v. 2, n. 2, p. 73-95, 2010.

DORIGON, C. O mercado informal dos produtos coloniais da região oeste de Santa Catarina. In: I Encontro Luso-Brasileiro de Estudos do Consumo. Anais... Rio de Janeiro, 2010. 
ELLIS, F. Household strategies and rural livelihood diversification. Journal of Development Studies, v. 35, n. 1, p. 1-38, 1998.

FENSTERSEIFER, J. E. Internacionalização e Cooperação: dois imperativos para a empresa do terceiro milênio. READ, v. 6, n. 3, p. 1-9, 2000.

FOGUESATTO, C. R.; MACHADO, J. A. D. O processo decisório na criação de unidades que agregam valor á produção agropecuária: as agroindústrias familiares. Desenvolvimento em Questão, v. 15, n. 39, p. 301-319, 2017a.

FOGUESATTO, C. R.; MACHADO, J. A. D. Perceptions of risk and risk management strategies in family agroindustries. African Journal of Agricultural Research, v. 12, n. 22, p. 1881-1888, $2017 \mathrm{~b}$.

FONTANELLA, B. J. B. et al. Amostragem por saturação em pesquisas qualitativas em saúde: contribuições teóricas. Cadernos de Saúde Pública, v.24, n. 1, p.17-27, 2008.

GAZOLLA, M. Conhecimentos, produção de novidades e ações institucionais: cadeias curtas das agroindústrias familiares. 292 f. Tese (Doutorado - Desenvolvimento Rural) Programa de Pós-Graduação em Desenvolvimento Rural, Universidade Federal do Rio Grande do Sul, Porto Alegre, 2012.

GAZOLLA, M.; SCHNEIDER, S. Conhecimentos, produção de novidades e transições sociotécnicas nas agroindústrias familiares. Organizações Rurais e Agroindustriais, v. 17, n. 2, p. 179-194, 2015.

IBGE - INSTITUTO BRASILEIRO DE GEOGRAFIA E ESTATÍSTICA. Censo Agro 2006: IBGE revela retrato do Brasil agrário. 2009. Disponível em:

<http://censo2010.ibge.gov.br/pt/noticias?view=noticia\&id $=1 \& i d n o t i c i a=1464 \&$ busca $=1 \& \mathrm{t}=$ censo-agro-2006-ibge-revela-retrato-brasil-agrario>. Acesso em: 13 de nov. 2015.

KAGEYAMA, A. Diversificação das rendas nos domicílios agrícolas no Brasil, 1992 e 2001. Economia e Sociedade, v. 12, n. 1, p. 65-86, 2003.

LANDAU, E. C. et al. Variação geográfica do tamanho dos módulos fiscais no Brasil. Sete Lagoas: Embrapa Milho e Sorgo, 2012.

MATEI, A. P.; XAVIER da SILVA, L. Interações com o ambiente institucional nas agroindústrias familiares gaúchas. Redes, v. 21, n. 3, p.358-377, 2016.

MIOR, L. C. Agricultores familiares, agroindústrias e redes de desenvolvimento rural. Chapecó: Argus, 2005.

NEITZKE, D. F.; FAVARÃO, S. C. M.; SANTOS, M. Z. dos. Perfil das Agroindústrias Familiares Situadas na Região Centro-Ocidental do Estado do Paraná. Revista em Agronegócio e Meio Ambiente, v. 7, n. 2, p. 279-293, 2014.

NIEDERLE, P. A.; WESZ JUNIOR, V. J. A agroindústria familiar na região Missões: construção de autonomia e diversificação dos meios de vida. Redes, v. 14, n. 3, p. 75-102, 2009. 
PELINSKI, A. et al. A diversificação no incremento da renda da propriedade familiar agroecológica. In: I Congresso Brasileiro de Agroecologia. Anais... Belo Horizonte, 2006.

PELEGRINI, G. GAZOLLA, M. A agroindústria familiar no Rio Grande do Sul: limites e potencialidades a sua representação social. Frederico Westphalen: URI, 2008.

PREZOTTO, L. L. Uma concepção da agroindústria rural de pequeno porte. Revista de Ciências Humanas, n. 31, p. 133-153, 2002.

RIO GRANDE DO SUL. Secretaria do Desenvolvimento Rural, Pesca e Cooperativismo. Programa Estadual de Agroindústria Familiar. Manual Operativo. Porto Alegre, maio, 2013. $14 \mathrm{p}$.

RUIZ, M. S. et al. Agroindústria familiar de Londrina. Unopar Científica Ciências Jurídicas e Empresariais, v. 3, n. 2, p.7-13, 2002.

SCHNEIDER, S. Teoria Social, agricultura familiar e pluriatividade. Revista Brasileira de Ciências Sociais, v. 18, n. 51, p. 99-121, 2003.

SCHNEIDER, S.; CAZELLA, A. A.; MATTEI, L. Histórico, caracterização e dinâmica recente do Pronaf - Programa Nacional de Fortalecimento da Agricultura Familiar. In: SCHNEIDER, S.; SILVA, M. C.; MARQUES, P. E. M. (Org.). Políticas públicas e participação social no Brasil rural. Porto Alegre-RS: Editora da UFRGS, 2004, p. 21-49.

TERNOSKI, S.; PERONDI, M. Â. As estratégias de diversificação dos meios de vida e a formação da renda: uma análise empírica sobre os estabelecimentos agrícolas familiares cooperados da Cresol Prudentópolis. Revista Teoria e Evidência Econômica, v. 20, n. 43, p. 283-312, 2014.

TEIXEIRA, J. C. Modernização da agricultura no Brasil: impactos econômicos, sociais e ambientais. Revista Eletrônica da Associação dos Geógrafos Brasileiros, v. 1, n. 2, p. 2142, 2005.

VEIGA, J. E. da. Agricultura familiar e sustentabilidade. Cadernos de Ciência \& Tecnologia, v. 13, n. 3, p. 383-404, 1996.

WAQUIL, P. D.; MIELE, M.; SCHULTZ, G. Mercados e comercialização de produtos agrícolas. Porto Alegre: Editora da UFRGS, 2010.

WESZ JUNIOR, V. J. Agroindústria familiar: um mecanismo de estimulo à especialização das atividades na propriedade rural? Mundo Agrário, v. 9, n. 18, 2009.

WINCK, C. A. et al. Agricultura familiar e rendas alternativas na região da Quarta Colônia/RS. Revista Brasileira de Gestão e Desenvolvimento Regional, v. 10, n. 1, p. 28$51,2014$. 